\title{
ECMO (Extracorporeal membrane oxygenation) experience in severe ARDS (Acute respiratory distress syndrome) due to COVID-19
}

\author{
MINE ÇAVUŞ 1
}

${ }^{1}$ Affiliation not available

December 20, 2020

\begin{abstract}
Lung infections caused by COVID-19; it can progress to severe ARDS with a high mortality.ECMO treatment is among the treatments applied in ARDS due to COVID-19.In this case report; It was aimed to discuss the results of ECMO treatment in ARDS developing due to COVID-19.
\end{abstract}

ECMO (Extracorporeal membrane oxygenation) experience in severe ARDS (Acute respiratory distress syndrome) due to COVID-19

\section{Mine Altınkaya Çavuş}

Department of Intensive Care, University of Health Sciences, Kayseri City Hospital, Kayseri, Turkey

Mine Altınkaya Çavuş, $M D$

Department of Intensive Care, University of Health Sciences, Kayseri City Hospital, Kayseri, Turkey

email:minealtinkaya@yahoo.com

Phone: $+90533-7332458$

ORCID: 0000-0003-2584-0463 (corresponding author)

ECMO (Extracorporeal membrane oxygenation) experience in severe ARDS (Acute respiratory distress syndrome) due to COVID-19

Abstract

Lung infections caused by COVID-19; it can progress to severe ARDS with a high mortality.ECMO treatment is among the treatments applied in ARDS due to COVID-19.In this case report; It was aimed to discuss the results of ECMO treatment in ARDS developing due to COVID-19. Approval of patient relatives was obtained for the publication of the article.

Introduction

Coronavirus disease 2019 (COVID-19) severe acute respiratory syndrome coronavirus 2 (SARS-CO-V-2) is a member of betacoronavirus. The COVID-19 outbreak was first seen in Wuhan, China's Hubei province. It quickly spread to over 50 cities in December 2019 (1). Lung infections caused by COVID-19; it can progress to severe acute respiratory distress syndrome (ARDS) with a high mortality. Treatment strategies are not based on precise data, but the evidence is increasing day by day. 
In general, ARDS means that if the partial pressure of oxygen $(\mathrm{PaO} 2) /$ inspired oxygen fraction (FiO2) in the arterial blood is between 200 and $300 \mathrm{mmHg}$, ARDS is mild; Medium if $\mathrm{PaO} 2$ / FiO2 value is between 100 and $200 \mathrm{mmHg}$; and if $\mathrm{PaO} 2$ / FiO2 is less than $100 \mathrm{mmHg}$, it is classified as severe. should be treated accordingly (2)

Extracorporeal membrane oxygenation (ECMO) is a treatment method that provides cardiopulmonary support in life-threatening heart and lung failure. In this treatment approach, the patient's blood is taken into the machine by cannulation from a large vein, and the blood is given to the patient again through a large vein after the blood is oxygenated. This method is similar to the procedure performed in coronary bypass surgery [3]. There are 2 types of ECMO, veno-arterial and veno-venous [4,5].

In this case report; It was aimed to discuss the results of ECMO treatment in ARDS developing due to COVID-19. Approval of patient relatives was obtained for the publication of the article.

\section{Case}

A 51-year-old male patient who was admitted to the hospital with fever, sputum, and cough for 3-4 days was admitted to the pandemic ward. Favipiravir and azithromycin treatment was initiated for the patient who did not have contact history and additional disease. The patient was transferred to the 3rd step intensive care unit due to tachypnea and desaturation on the 6th day of hospitalization. Progression was observed in the infiltrations in the computerized torax tomography. Tasoluzimab was added to the treatment. Intubation decision was made for the patient whose saturation was between $54-57 \%$ and whose lactate values increased with non-invasive mechanical ventilation on the 18th day of intensive care admission (table 1). Mechanical ventilation settings after intubation; Despite the support of $100 \% \mathrm{fiO} 2,10 \mathrm{cmH} 2 \mathrm{O}$ peep, 24 respiratory rate, $20 \mathrm{cmH} 2 \mathrm{O}$ pressure support, ECMO was applied to the patient whose saturation was $63 \%$. ECMO flow rate applied peripherally venous-venous was set as $3.6 \mathrm{lt}$, fiO2 100\%. Pulse steroid treatment was added (1 g of methylprednizalone for 3 days). During follow-up, the saturation values found $90 \%$ at the $3 \mathrm{rd}$ and $12 \mathrm{th}$ hours. Anticoagulation was performed with heparin. ACT (activated coagulation time) was kept between 200-250. For 13 days; There were no complications other than minor bleeding around the cannula. The daily fluid balance of the patient, whose laboratory parameters were within normal limits, was monitored, and inotropic support was not needed until the last day. Erythrocyte transfusion was performed with a hemoglobin value of $10 \mathrm{mg} / \mathrm{dl}$.

On the 8th and 9th days of ECMO, a decrease in the flow rate and fiO2 was tried, but the patient could not tolerate. 13th day saturations decreased to $70 \%$ numbers. ECMO has lost its membrane function; The ECMO was evaluated with inlet and outlet blood gases (table 1). It was observed that there was no change in the saturation of the patient whose ECMO supports were lowered. During the 13-day ECMO treatment, no change in mechanical ventilation settings could be made, and the lung capacity of the patient did not improve. ECMO cannulae were removed, membrane change was not considered. The mean arterial pressure of the patient who was followed up as desaturated fell. Dopamine and steradin infusion was started. The patient died 1 day after ECMO was removed.

Table1: Blood gas values of the patient according to days

\begin{tabular}{lllll}
\hline Blood gases & Before intubation & After intubation & Ecmo3th hours & Ecmo 12th hours \\
\hline Po2(mmHg) & 32.9 & 34.8 & 54 & 61.1 \\
Pco2(mmHg) & 38.5 & 32.7 & 29.1 & 36 \\
Ph & 7.32 & 7.42 & 7.49 & 7.43 \\
Saturation \% & 57 & 63.4 & 90.6 & 91.5 \\
Lactate $(\mathrm{mmol} / \mathrm{l})$ & 2.3 & 1.6 & 1.2 & 1 \\
& 13 th day ecmo & 13 th day ecmo & 13 th day artery & Ecmo weaning \\
& login & exit & & \\
Po2(mmHg) & 21.3 & 27.5 & 33.7 & 38.4 \\
Pco2(mmgr) & 30.1 & 25.9 & 30.1 & 41.8
\end{tabular}




\begin{tabular}{lllll}
\hline Blood gases & Before intubation & After intubation & Ecmo3th hours & Ecmo 12th hours \\
\hline Ph & 7.57 & 7.61 & 7.57 & 7.44 \\
Saturation \% & 40.9 & 61.1 & 73 & 70.3 \\
Lactate $(\mathrm{mmol} / \mathrm{l})$ & 1.9 & 2 & 2.2 & 2 \\
\hline
\end{tabular}

Discussion

Extracorporeal membrane oxygenation (ECMO); It is a temporary method used in patients with lifethreatening, advanced but curable pulmonary or cardiac failure (or both) while waiting for the organs to recover. Clinical experience, foresight and common sense are important to begin ECMO therapy.

The current indication for ECMO that can be summarized; There are some criteria for patient selection in the registries of the Extracorporeal Life Support Organization (ELSO) because there is "unresponsiveness to conventional treatment". In terms of cardiac failure; The most common indications for ECMO use are post-cardiotomy (situations where the patient cannot be separated from cardiopulmonary bypass after cardiac surgery), post-heart transplant (usually in graft failure) and other severe advanced heart failure (e.g. decompensated cardiomyopathy, myocarditis, acute coronary syndrome accompanied by cardiogenic shock). deep cardiac depression, refractory arrhythmias, pulmonary embolism, acute anaphylaxis or isolated cardiac trauma) due to drug overdose or sepsis $(6,7)$. In terms of respiratory insufficiency; The most common indication can be listed as ARDS (adult respiratory distress syndrome), pneumonia, aspiration, trauma or primary graft failure after lung transplantation (8).

ECMO allows to reduce the stress on the ventilated lung at high airway pressures that may damage the lung, so it should be recommended for patients with refractory hypoxemia or hypercapnia despite optimal ventilation (9)

The fact that the H1N1 influenza epidemic in 2009 caused many people to enter severe ARDS and refractory hypoxemia, reintroduced the use of ECMO in combination with protective ventilation $(10,11)$ and its use by young clinicians in patients without comorbidities gained popularity.

According to the CESAR study, which is one of the most comprehensive studies on adults, ECMO has been shown to be beneficial when administered in adults due to ARDS (12). In the Australia-Alfred study involving 151 patients between 2005 and 2011, the results of VA-ECMO (66.5\%) and VV-ECMO (33.5\%) were compared. Average application time, in order; It was 10 days (6-16) and 7 days (5-10) and the results were compared. Total mortality was $37.3 \%, 37.1 \%$ for VA-ECMO and $37.7 \%$ for VV-ECMO. The most common complications were bleeding and infection (13).

Zhou et al., Chen et al., Yang et al. In their studies, satisfactory results could not be obtained with ECMO applied in a limited number of ARDS patients with COVID-19. ECMO 'weaning could not occur in any $(14,15,16)$,

As long as conditions such as cardiac and pulmonary insufficiency continue to be life-threatening for patients of all ages; Searches and detailed studies on ECMO or other alternative methods will continue.

Funding: None

Conflict of Interest: None

Data availability statement

Literatures

1. Lu R, Zhao X, Li J, Niu P, Yang B, Wu H, et al. Genomic characterisation and epidemiology of 2019 novel coronavirus: implications for virus origins and receptor binding. Lancet 2020; 395(10224):565e74. 
2. Akar AR, Ertugay S,Kervan Ü, İnan MB, Sargın M, Engin Ç, Özatik MA . Turkish Society of Cardiovascular Surgery (TSCVS) Proposal for use of ECMO in respiratory and circulatory failure in COVID-19 pandemic era. tgkdc.dergisi. 2020;28(2):229-235

3. What is ECMO? Am J Respir Crit Care Med.2016;193(6):9-10.

4. Trittenwein G, Furst G, Golej J, Frenzel K, Burda G, Hermon M, et al. Preoperative ECMO in congenital cyanotic heart disease using the AREC system. Ann Thorac Surg. 1997;63:1298-302.

5. Duncan BW, Hraska V, Jonas RA, Wessel DL, Del Nido PJ, Laussen PC, et al. Mechanical circulatory support in children with cardiac disease. J Thoracardiovasc Surg. 1999;117:529-42.

6. Fiser SM, Tribble CG, Kaza AK, Long SM, Zacour RK, Kern JA, et al. When to discontinue extracorporeal membrane oxygenation for postcardiotomy support. Ann Thorac Surg 2001;71:210-4.

7. Marasco SF, Esmore DS, Negri J, Rowland M, Newcomb A, Rosenfeldt FL, et al. Early institution of mechanical support improves outcomes in primary cardiac allograft failure. J Heart Lung Transplant $2005 ; 24: 2037-42$.

8. Ferguson ND, Fan E, Camporota L, Antonelli M, Anzueto A, Beale R, et al.The Berlin definition of ARDS: an expanded rationale, justification, and supplementary material. Intensive Care Med 2012;38:1573-82.

9. Gattinoni L, Pesenti A, Mascheroni D, Marcolin R, Fumagalli R, Rossi F, et al. Low-frequency positivepressure ventilation with extracorporeal CO2 removal in severe acute respiratory failure. JAMA 1986;256:8816.

10. Abrams D, Brodie D, Combes A. What is new in extracorporeal membrane oxygenation for ARDS in adults? Intensive Care Med 2013;39:2028-30.

11. Australia and New Zealand Extracorporeal Membrane Oxygenation (ANZ ECMO) Influenza Investigators, Davies A, Jones D, Bailey M, Beca J, Bellomo R, Blackwell N, et al. Extracorporeal membrane oxygenation for 2009 influenza A (H1N1) acute respiratory distress syndrome. JAMA 2009;302:1888-95.

12. Peek GJ, Mugford M, Tiruvoipati R, Wilson A, Allen E, Thalanany MM, et al. Efficacy and economic assessment of conventional ventilatory support versus extracorporeal membrane oxygenation for severe adult respiratory failure (CESAR): a multicentre randomised controlled trial. Lancet 2009;374:1351-63.

13. Aubron C, Cheng AC, Pilcher D, Leong T, Magrin G, Cooper DJ, et al. Factors associated with outcomes of patients on extracorporeal membrane oxygenation support: a 5-year cohort study. Crit Care 2013;17:73.

14. Zhou F, Yu T, Du R, Fan G, Liu Y, Liu Z, et al. Clinical course and risk factors for mortality of adult inpatients with COVID-19 in Wuhan, China: a retrospective cohort study. Lancet 2020:S0140-6736(20)305663 .

15. Chen N, Zhou M, Dong X, Qu J, Gong F, Han Y, et al. Epidemiological and clinical characteristics of 99 cases of 2019 novel coronavirus pneumonia in Wuhan, China: a descriptive study. Lancet 2020;395:507-13.

16. Yang X, Yu Y, Xu J, Shu H, Xia J, Liu H, et al. Clinical course and outcomes of critically ill patients with SARSCoV- 2 pneumonia in Wuhan, China: a single-centered, retrospective, observational study. Lancet Respir Med 2020: S2213-2600(20)30079-5.

\section{Hosted file}

Table ecmo.pdf available at https://authorea.com/users/383226/articles/499791-ecmoextracorporeal-membrane-oxygenation-experience-in-severe-ards-acute-respiratory-

distress-syndrome-due-to-covid-19 


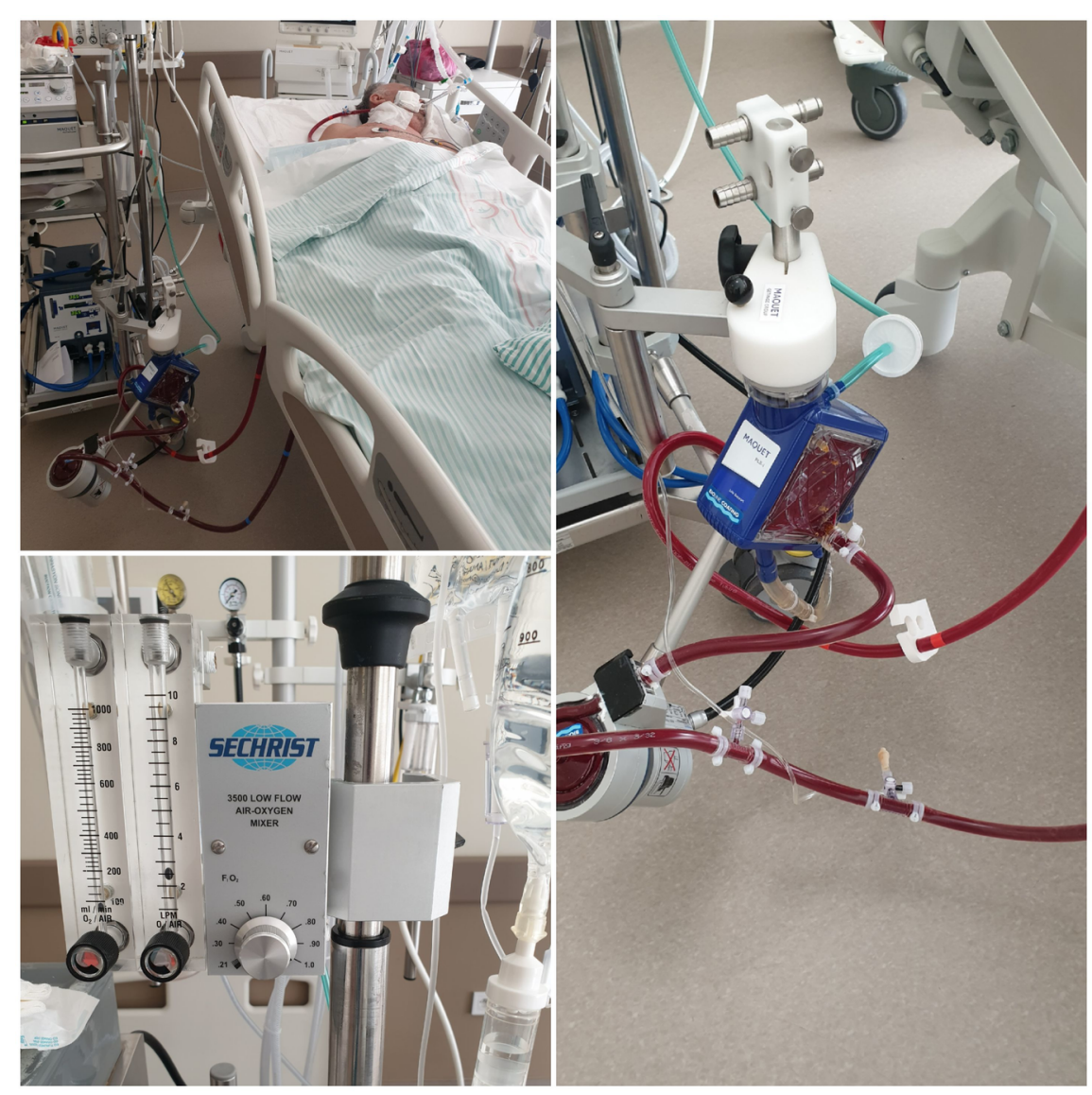

